\section{Cow gore related orofacial injuries: Evaluation of cases managed at a semi-urban Hospital in Nigeria}

\author{
Thomas Owobu, ${ }^{1}$ Basil T. Ojukwu, ${ }^{2}$ Auwal S. Balarabe, ${ }^{3}$ \\ Babatunde O. Bamgbose ${ }^{5^{*}}$
}

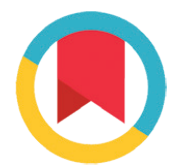

CrossMark

\title{
Abstract
}

Objective: This study evaluated such cases with oro-facial injuries as presented at the hospital for the period of seven years.

Material and Methods: The study sample size consists of a total of 22 patients who had various degrees of orofacial injuries were seen and managed during the period of study. Although some of the case were considered severe, there was no fatality recorded during the period under review. Some patients with soft tissues avulsion at any part of the body revealed jagged wound edges and, in some cases, the wounds were still bleeding at the time of presentation.

Results: A total of 22 patients of which 19 were males (86.36\%) and 3 females (13.64\%) were received and treated at the Oral and
Maxillofacial department during the period under review. A gender ratio of male to female, $6.33: 1$, was recorded. $14(63.64 \%)$ of the number had fracture of oro-facial bone. The data were analyzed using statistical package for social sciences (SPSS) version 20.0 (SPSS Inc, (hicago, IL).

Conclusion: Farm safety experts estimate that more than half of cow injuries can be prevented by using some type of personal protective equipment, depending on the work activity. Unfortunately, most herders in developing world does not have this protective equipment thereby increasing the risk or frequently sustaining injuries from cow attacks.

Keywords: Cow gore, Oro- facial injuries, Semi- urban Hospital, Nigeria

Cite this Article: Owobu T, 0jukwu BT, Balarabe AS, Bamgbose BO. 2020. Cow gore related orofacial injuries: Evaluation of cases managed at a semi- urban Hospital in Nigeria. Journal of Dentomaxillofacial Science 5(3): 141-145. D0I: 10.15562/jdmfs.v5i3.1118

'Department of Dental and Maxillofacial, Federal Medical Center, Nguru, Yobe State, Nigeria ${ }^{2}$ Department of Public Health, Intercountry Center for Oral Health (ICOH), Jos, Plateau State, Nigeria ${ }^{3}$ Department of Child Dental Health, Faculty of Dentistry, Bayero University Kano, Kano, Nigeria ${ }^{4}$ Department of Oral Diagnostic Sciences, Faculty of Dentistry, Bayero University Kano, Kano, Nigeria

${ }^{5}$ Department of Oral and Maxillofacial Radiology, Okayama University Graduate School of Medicine, Dentistry and Pharmaceutical Sciences, Okayama, Japan

*Correspondence to:

Babatunde 0. Bamgbose, Department of Oral and Maxillofacial Radiology, Okayama University Graduate School of Medicine, Dentistry and Pharmaceutical Sciences, Okayama, Japan drtundebamgbose@yahoo.com

Received: 13 January 2020

Revised: 10 June 2020

Accepted: 9 July 2020

Available Online: 1 December 2020

\section{Introduction}

Cows are socioeconomically important domestic animals and adored in some parts of the world especially where cows are regarded as objects of religious worship. ${ }^{1-3}$ Cows like other domestic animals have frequent and close contact with humans. Injuries and deaths related to contact with cows do occur especially when the animal feels perturbed. The size and strength of these animals make associated injuries significant especially when it occurs on the orofacial tissues. Although most of these injuries are not well documented, however, the associated trauma related injuries have specific presentation and are usually connected to particular activities. ${ }^{1,2-5}$ Studies have identified groups such as dairy farmers, veterinarians and abattoir workers to be at a higher risk of injury. ${ }^{2,3,6}$ The risk of injury to the general public also increases just by being near the cattle. Injuries or fatality recoded were as a result of kicking, crushing, head butting and trampling. There is often an urgent need for first aid treatment or hospitalization in some cases as these injuries usually occur as an out-door event. Soft tissue avulsion/laceration as well as contusions and fractures, are the most common consequences. Case assessment and treatment of injuries due to cattle trauma should follow some clear and welldefined principles. ${ }^{1,3-8}$
This present study is a review of patients with cow gore injury who were managed at a semi urban hospital setting.

\section{Material and Methods}

This was a retrospective review of records of patients who underwent various treatments on account of orofacial cow gore injuries over a sevenyear period (January 2008 to December 2014) in dental and maxillofacial department of Federal Medical Centre, Nguru, Yobe State. The sources of clinical information were clinic attendance registers, patient medical records, clinic procedure registers, accident and emergency registers, and operating theatre records. Information collated include patients' age, gender, patients' occupation, type of injury, duration of hospital stays and type of treatment carried out. A review of management protocol, analgesic and antibiotic therapy was also done. The study protocol was exempted by Ethics review committee of the hospital because is a retrospective review of records of patients. The study sample size consists of a total of 22 patients who had various degrees of orofacial injuries were seen and managed during the period of study. Although some of the case were considered severe, there was no fatality recorded during the period under review. Some patients with soft tissues avulsion at 
any part of the body revealed jagged wound edges and, in some cases, the wounds were still bleeding at the time of presentation. Facial soft tissues injuries were thoroughly evaluated and sutured due to their cosmetic importance. Anatomical aspects of the face were taken into consideration to minimize flap/wound edge necrosis. The conservative/ non-surgical management for those with fracture of facial bone employed entailes the use of antibiotics (cefuroxime/Zinnat tablets 500mg 12 hourly for 5 days and metronidazole/Flagyl tablets $400 \mathrm{mg}$ 8 hourly for 5 days), analgesics diclofenac/Cataflam tablets 50mg 12 hourly for 3 days, warm saline mouth rinses before and after meals, feeding on soft diet and regular weekly follow up.

Reduction of bone fractures were done and immobilization achieved using either eyelet wires or mini-bone plates and screws.

The data were analyzed using statistical package for social sciences (SPSS) version 15.0 (SPSS Inc, Chicago, IL). Absolute numbers and simple percentages were used to describe categorical variables. Quantitative variables were described using measures of central tendency (mean, median) and measures of dispersion (range, standard deviation) as appropriate. No tests of significance were done.

\section{Results}

A total of 22 patients of which 19 were males $(86.36 \%)$ and 3 were females (13.64\%) were seen during the period of the study. A gender ratio of 6.33 $: 1$ was recorded. The ages of these patients ranged from 6 years to 60 years with a mean value of 32 years \pm 4 years. Laceration was the commonest soft tissue injury noted (68.18\%) while Mandibular fracture was the commonest hard tissue injury. Zygomatic complex and frontal bone fractures, isolated zygomatic arch and Le-fort fractures recorded lower frequencies table 1 and table 2. All the female victims had one form of fracture or the other.

\section{Socio-demographic factors}

Table 1 revealed a slightly different Sociodemographic factors. ${ }^{9}$ A total of 22 patients of which 19 were males $(86.36 \%)$ and 3 females (13.64\%) were seen during the period of the study. A gender ratio of $6.33: 1$ was recorded. Almajiri (Homeless children under the custody of a local

\section{Table 1 Social demographic characteristic and type of injury sustained by patients}

\begin{tabular}{|c|c|c|c|c|c|c|}
\hline \multirow[b]{2}{*}{$\mathbf{S} / \mathbf{N}$} & \multirow[b]{2}{*}{ Sex } & \multirow[b]{2}{*}{ Age } & \multirow[b]{2}{*}{ Occupation } & \multicolumn{3}{|c|}{ Types of Injuries } \\
\hline & & & & Soft tissue & Contusion & Fractures laceration \\
\hline 1. & $\mathrm{M}$ & 6 & Almajiri & + & - & - \\
\hline 2 & M & 9 & Almajiri & + & - & - \\
\hline 3. & M & 37 & Cow handler & + & - & - \\
\hline 4. & $\mathrm{~F}$ & 25 & Cow handler & + & + & + \\
\hline 5. & $\mathrm{M}$ & 15 & Cow handler & - & + & + \\
\hline 6. & M & 54 & Cow handler & + & + & - \\
\hline 7. & M & 10 & Almajiri & + & + & + \\
\hline 8. & $\mathrm{~F}$ & 33 & Housewife & + & + & + \\
\hline 9. & M & 45 & Cow handler & - & + & + \\
\hline 10. & M & 41 & Transporter & + & - & - \\
\hline 11. & M & 9 & Almajiri & - & - & + \\
\hline 12. & M & 12 & Cow handler & - & + & - \\
\hline 13. & $\mathrm{M}$ & 23 & Cow handler & + & + & + \\
\hline 14 & M & 56 & Cow handler & - & + & + \\
\hline 15. & M & 45 & Transporter & + & + & + \\
\hline 16. & $\mathrm{~F}$ & 15 & Student & + & + & + \\
\hline 17. & $\mathrm{M}$ & 16 & Cow handler & - & + & + \\
\hline 18. & M & 56 & Cow handler & + & + & + \\
\hline 19. & M & 53 & transporter & + & - & - \\
\hline 20. & M & 60 & Cow handler & + & + & + \\
\hline 21. & $\mathrm{M}$ & 35 & Transporter & + & + & + \\
\hline
\end{tabular}


Table 2 Facial fracture distribution amongst the patients

\begin{tabular}{lcccc}
\hline & Male (N\%) & Female (N\%) & & Total (N\%) \\
\hline Frontal bone fracture & $2(14.29)$ & $1(7.14)$ & $3(21.43)$ \\
Zygomatic complex fracture & $3(21.43)$ & - & $3(21.43)$ \\
Isolated zygomatic fracture & $1(7.14)$ & $1(7.14)$ & $2(14.29)$ \\
Le-fort fracture & $1(7.14)$ & - & $1(7.14)$ \\
Mandibular fractures & $4(28.57)$ & $1(7.17)$ & $5(37.71)$ \\
Total & $11(78.57)$ & $3(21.43)$ & $14(100)$ \\
\hline
\end{tabular}

Quranic Teacher) were 4(9.09\%). The study population belonged to Hausas/Fulanis.

\section{Discussion}

Facial soft and hard tissue injuries following cow attack are not uncommon. In most of these attacks, health and life can be threatened by the direct effect of the trauma (crushing, kicking and hitting) or by complications of wounds infections. ${ }^{10}$ The size and sometimes, the speed of cow creates forces like those which occur in motor vehicle accidents and sometimes can be devastating., ${ }^{4,5}$

Handling of herds of cow is a risk prone occupation, ${ }^{6-8}$ farmers often over- look this risk aspect of their business since it remains the only source of their income. When injury occurs following an attack, it is usually taken as part of the risk involved and occupational hazard.

From the experience of the authors and eye witness account, most of these attacks occur during feeding of the cows, moving cows to different locations, loading cows into trucks/trailers, artificial insemination, grooming, basic animal care such as hoof care and dehorning. Other activities following which attack could occur includes cleaning animals, roping animals, applying topical insecticides, giving vaccinations, applying topical or administering oral medications, castrating, pulling teeth, ear tagging, milking, branding, shoeing, assisting with delivery of newborns, and assisting veterinarians with treatment or handling of injured animals.

Generally, livestock farming may be associated with significant risk especially where training is lacking or inadequate..$^{6-8}$ World Health Organization predicted that by the year 2020, cows and other animals related injuries will be responsible for more death, morbidity, and disability than all communicable diseases combined ${ }^{10,11}$ that injuries account for 1 in 7 potential life-years lost worldwide, but by 2020 they will account for 1 in 5, with the developing countries bearing the brunt of this increase. Prevention and injury control have gained attention and enormous support with the infusion of funding for injury control in developed countries and particularly the creation of the National Center for Injury Control and Prevention within the Centers for Disease Control and Prevention in the United States. ${ }^{12}$ Unfortunately, similar program is yet to be developed in most developing countries. During the last decade of the 20th century, workers in the United States agricultural industry received particular attention because of the high risk of fatal injuries and suspected risk for serious non-fatal injuries. ${ }^{13}$

Most studies have revealed that livestock handling activities are the second or third leading cause of injuries on the farm, causing from $12 \%$ to $24 \%$ of farm injuries. ${ }^{4,6}$ Available records in developed countries estimated that about 30 farmers are killed each year from contact with farm animals, primarily horses and cattle. Dairy bulls may be more likely to injure humans than beef bulls. Dairy bulls generally have more frequent contact with humans than do beef cattle and are known to be possessive of their herd and occasionally disrupt routine feeding, cleaning, and milking operations. ${ }^{9}$

\section{Clinical evaluation of patient with cattle injuries}

Traumatic facial soft and hard tissue injuries following cow attack require multi-disciplinary team approach. ${ }^{15,16}$ Trauma physicians must evaluate carefully, triage properly and maintain a high index of suspicion to improve survival and enhance functional recovery. Information about mechanism of injury often suggests a non-specific pattern. ${ }^{9}$ Other sites noted were the extremity, thorax and abdomen. Physical examination with immediate attention given to problems associated with airway compromise and hemorrhage. Other critical injuries must be ruled out, including intracranial hemorrhages, cervical and other spinal injuries, chest injuries, abdominal trauma and fracture of long bones. It has been noted that patients with multiple trauma often have facial fractures and conversely patients with facial fractures often have other concomitant injuries. ${ }^{17}$

Once the airway, breathing and circulation have been adequately assessed, neurologic evaluation would follow. Standard trauma protocols such as those described in Advanced Trauma Life Support guidelines of America Red Cross should be used during a comprehensive examination. ${ }^{17}$ Accurate history which is followed by a thorough clinical examination should also be obtained from the patient or relative if the patient cannot communicate.

\section{Modalities for treatment of soft tissues}

Facial soft-tissue injury complications include, but are not limited to, infection, hematoma, poor cosmetics, flap/wound edge necrosis. Facial soft 
tissues avulsions and lacerations warrant a detailed and meticulous approach to evaluation due to their cosmetic importance. Patients are often concerned about the possible outcome. Familiarity with the pertinent anatomical aspects of the face is important. For most of the cases, the wound was thoroughly explored, copiously irrigated with normal saline solution, cleaned, and debrided of devitalized tissue before closure. The anatomical boundaries were respected and carefully realigned to avoid obvious deformity.

\section{Modalities of treatment for mandibular fractures}

The general principles of treatment of facial bone fractures following cattle attack do not differ essentially from the treatment of fractures elsewhere in the body. ${ }^{18}$ This principle involves reducing the bone fragments into proper anatomical alignment, then immobilizing the fracture segments until bone union occurs with or without the use of intermaxillary fixation. For example, open or closed reduction of mandibular fractures was employed in the present study, followed by immobilization of the fractured segments with either internal or intermaxillary fixation is the accepted standard of treatment for facial bone fractures. ${ }^{19,20}$

The choice of treatment for patient with maxillofacial fractures was influenced by several factors such $\mathrm{s}^{21,22}$ patients' age, type of fracture, associated or concomitant injury and soft tissue lacerations. Other factors that affect the choice of treatment include infection, time of presentation, dentate versus edentulous mandible, equipment available and surgeon's skill and experience.

Fonseca et al..$^{23}$ in a review of literature on the principles of treatment of mandibular fractures gave the following guidelines; the patient's general physical status should be carefully evaluated and monitored prior to any consideration of treating mandibular fractures; diagnosis and treatment of mandibular fractures should be approached methodically and not with an "emergency-type" mentality. This is because patients rarely die of mandibular fractures, so there is time to evaluate carefully and thoroughly, the nature and extent of mandibular injuries; dental injuries should be evaluated and treated concurrently with the treatment of mandibular fractures. Fractured teeth can become infected and jeopardize bone union. An intact tooth in the line of fracture that is maintaining bone fractures should be protected with antibiotic coverage.

A second molar tooth on an otherwise edentulous posterior fracture segment should be maintained to prevent superior displacement of the fragment in intermaxillary fixation. Mandibular cuspids are cornerstones of occlusion and should be maintained as much as possible. Some teeth are not critical to occlusion and can be removed when their prognosis is doubtful and if maintained, might adversely affect fracture treatment. Some fractured teeth cannot be salvaged, no matter how critical they might be. ${ }^{23}$

Re-establishment of occlusion is the primary goal in the treatment of mandibular fractures. The mandible has an excellent blood supply and so, non-union is rare. The bone fragments do not have to be in tight approximation to heal. ${ }^{23}$

With multiple facial fractures, mandibular fractures should be treated first. Reconstruction of the mandible first forms the foundation upon which the other facial bones can be laid; although with the use of rigid fixation, deviation from this principle can be allowed. All intraoral surgery should be done prior to any extra oral open reduction or suturing of facial lacerations.

Intermaxillary fixation (IMF) time should vary according to the type, location, number and severity of the mandibular fracture, as well as the patient's age, health and method used for reduction and immobilization. Historically, a period of 6 weeks of IMF has been used to allow healing to occur. With the advent of rigid, internal fixation techniques, IMF might be eliminated or maintained with light elastics for short periods; Prophylactic antibiotics should be used for compound fractures. ${ }^{23}$ Nutritional needs should be closely monitored post-operatively. Excellent reduction and fixation techniques may fail in a patient with significant weight loss and catabolic nutritional status. Most mandibular fractures can be treated by closed reduction. Despite the current enthusiasm for open reduction and rigid fixation in the treatment of mandibular fractures. Closed reduction techniques have had a long history of success.

However, in this study there was no hospital record of any death following cow injury within the period under review. There are multiple reasons for this; Nigeria does not have accurate data of the number of herdsmen who move about with their cattle across the country. Also, in developed world where cattle ranching is practiced, cow attack can easily be noticed and documented adequately. Unlike in Nigeria where such attack may happen at a remote location. Absence of orthodox medicine and utilization of traditional cares may also account for the non-documentation of these injuries in our environment. There may never be accurate data on injury fatalities following cow attack in our hospitals until such a time when we have accurate data of herders in developing world as well as ranching. 


\section{Conclusion}

Farm safety experts estimate that more than half of cow injuries can be prevented by using some type of personal protective equipment, depending on the work activity. Use of safety glasses, gloves, long trousers, steel-toed work shoes, and a bump hat for activities such as handling bulls, hoof trimming, and shipping the animals may grossly reduce these cows related injuries. These types of equipment will reduce the injury potential to the head, feet, hands, and other parts of the body. Unfortunately, most herders in developing world does not have this protective equipment thereby increasing the risk or frequently sustaining injuries from cow attacks. In addition, continued research is needed on the prevention of work-related injuries in the context of specific commodities, focused on the strategies and management approaches that reduce the risk of injury to humans and enhance animal welfare.

\section{Acknowledgment}

None.

\section{Conflict of Interest}

The authors report no conflict of interest.

\section{References}

1. Wasadikar PP, Paunikar RG, Deshmuka SB. Bull horn injuries in rural India. J Indian Med Assoc 1997;19: 3-4

2. Langley RL, Hunter JL. Occupational fatalities due to animal-related events. Wilderness Environ Med 2001;12: 168-174.

3. Sabo SY, Yusufo LMD. Injuries from cow gore in adults among Fulani. Trop Doct 2007;37: 111-112.

4. Hemsworth PH, Coleman GJ, Barnett JL, et al. Relationships between human-animal interactions and productivity of commercial dairy cows. Anim Sci J 2000;78: 2821-2831.

5. Bury D, Langlois N, Byard RW. Animal-related fatalities--part I: characteristic autopsy findings and variable causes of death associated with blunt and sharp trauma. J Forensic Sci 2012;57: 370-374.

6. Rudloff U, Gonzalez V, Fernandez E, et al. Chirurgica Taurina: a 10-year experience of bullfight injuries. J Trauma 2006;61: 970-974.
7. Austin CC. Nonvenomous animal-related fatalities in the United States workplace, 1992-1994. J Agromed 1998;5: 5-16.

8. Bakkannavar SM, Monteiro FN, Bhagavath P, et al. Death by attack from a domestic buffalo. J Forensic Leg Med 2010;17: 102-104.

9. Dogan KH, Demirci S, Erkol Z, et al. Injuries and deaths occurring as a result of bull attack. J Agromedicine 2008;13: 191-196.

10. Brison RJ, Pickett CW. Nonfatal injuries in 117 eastern Ontario beef and dairy farms: A one-year study. Am J Ind Med 1992;21: 623-636.

11. Padilla-Fernandez B, Diaz Alferez FJ, Garcia MA, et al. Bladder neck rupture following perineal bull horn injury: a surgical challenge. Clin Med Insights Case Rep. 2012;5: 123-128.

12. Dubey IB, Mohanty D, Jain BK. Diverse presentation of spontaneous rupture of urinary bladder: review of two cases and literature. Am J Emerg Med 2012;30: 832.

13. Casey GM, Grant AM, Roerig AD, et al. Farm worker injuries associated with cows. AAOHN J 1997;45: 446-450.

14. Boyle D, Gerberich SG, Gibson RW, et al. Injury from dairy cattle activities. Epidemiol 1997;8: 37-41.

15. Saar PEH, Dimich-Ward KD, Kelly DC. et al. Farm injuries and fatalities in British Columbia, 1990-2000. Canadian J Public Health 2006;97: 100-104.

16. Katzen JT, Jarrahy R, Eby JB et al. Craniofacial and skull base trauma. J Trauma 2003;54: 1026-1034.

17. Risdon F. The surgical treatment of facial injuries. Can Med Assoc J 1938;38: 33-36.

18. Jones JK, Van-Sickels JE. Rigid fixation: A review of concepts and treatment of fractures. Oral Surg Oral Med Oral Pathol Oral Radiol Endod 1988;65: 13-18.

19. Posnick JC, Wells M, Pron GE. Paediatric facial fractures-evolving patterns of treatment. J Oral Maxillofac Surg 1993;51: 836-844.

20. Lizuka T, Randall T, Given O, et al. Maxillofacial fractures related to work accidents. J Craniomaxillofac Surg 1990;8: 255-259.

21. Nogalski A, Jankiewicz L, Cwik G, et al. Animal related injuries treated at the Department of Trauma and Emergency Medicine, Medical University of Lublin. Ann Agric Environ Med 2007;14: 57-61.

22. Ajike SO, Adebayo ET, Amanyiewe EU, et al. An epidemiological survey of maxillofacial fractures and concomitant injuries in Kaduna, Nigeria. Nig J Surg Res 2005;7: 251-255.

23. Fonseca RJ, Bruce R, Walker R. Trauma volume. Oral Maxillofac Surg Washington Manual 2001;1: 19-34.

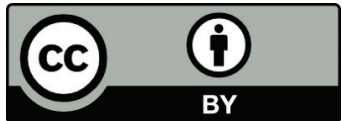

This work is licensed under a Creative Commons Attribution 